\title{
Barriers for guideline adherence in knee osteoarthritis care: a qualitative study from the patients' perspective
}

David Spitaels ${ }^{1}$ MD, Patrik Vankrunkelsven ${ }^{1}$ MD, Jurgen Desfosses ${ }^{2}$ MD, Frank Luyten ${ }^{3}$ MD, Sabine Verschueren ${ }^{4}$, Dieter Van Assche ${ }^{3,4}$, Bert Aertgeerts ${ }^{1} \mathrm{MD}$, Rosella Hermens $\mathbf{s}^{1,5}$

\footnotetext{
${ }^{1}$ Academic Center for General Practice, KU Leuven, Kapucijnenvoer 33 blok J, 3000 Leuven, Belgium

${ }^{2}$ General Practitioner, Watertorenlaan 2, 1930 Zaventem, Belgium

${ }^{3}$ Division of Rheumatology, University Hospitals Leuven, Herestraat 49, 3000 Leuven, Belgium

${ }^{4}$ Department of Rehabilitation Sciences, KU Leuven, Tervuursevest 101, 3001 Heverlee, Belgium

${ }^{5}$ IQ Healthcare, Radboud University Medical Center Nijmegen, PO Box 9101, 6500 HB Nijmegen, The Netherlands
}

\section{Email addresses}

DS: david.spitaels@kuleuven.be

PV: patrik.vankrunkelsven@kuleuven.be

JD: jurgen.desfosses@gmail.com

FL: frank.luyten@uzleuven.be

SV: sabine.verschueren@faber.kuleuven.be

DV: dieter.vanassche@uzleuven.be

BA: bert.aertgeerts@kuleuven.be

RH: rosella.hermens@radboudumc.nl

\section{Correspondence}

Dr. David Spitaels

Academic Center for General Practice

KU Leuven

Kapucijnenvoer 33, blok J, 3000 Leuven, Belgium

Telephone: +32(0)16377305

Fax: $+32(0) 16337480$

E-mail: david.spitaels@kuleuven.be

Word count (3199) 


\section{Abstract (250 words)}

Rationale, aims and objectives: Guidelines for patients with knee osteoarthritis (OA) are suboptimally implemented in clinical care. To improve guideline adherence, patients' perceived barriers and facilitators in current care were investigated.

Methods: Eleven patients with knee OA were extensively interviewed using a semi-structured script based on quality indicators. Directed content analysis, within the framework of Grol and Wensing, was performed to describe barriers and facilitators in six domains: the guideline, healthcare professional, patient, social environment, organization and financial context. Data were analyzed using NVIVO 10 software.

Results: In total, thirty-eight barriers, at all six domains, were identified. The most frequently mentioned barriers were in the domains of the patient and the healthcare professional, namely patients' disagreement with guidelines recommendations, negative experience with drugs, patients' limited comprehension of the disease process and poor communication by the healthcare professional. The patients' disagreement with recommendations is further explained by the following barriers: 'insistence on medical imaging', 'fear that physiotherapy aggravates pain' and 'perception that knee $O A$ is not a priority health issue'. Patients also reported 20 facilitators, all of which are listed as opposing barriers.

Conclusions: Patients indicate that both personal factors as well as factors related to healthcare professionals play an important role in non-adherence. An interview script, based on quality indicators, was a significant aid to structurally formulate barriers and facilitators in the perceived knee OA care. Future guideline implementation strategies should take the identified barriers and facilitators into account.

Key words: knee osteoarthritis, qualitative research, implementation, decision making, facilitators, non-adherence

\section{Introduction}

Osteoarthritis (OA) is a common joint disease and a leading cause of pain and disability, due to its predilection for low extremity joints such as knees and hips [1]. Worldwide approximately 250 million people (3.6\% of the global population) have knee OA [2]. Important risk factors are obesity, age, female sex, malalignment and previous knee injury [3]. By 2040, it is expected that the number of patients with knee OA will double worldwide due to the increasing obesity and the rising life expectancy [4]. Hence, knee OA will become a substantial burden for healthcare systems around the world in the near future [5].

To date, numerous guidelines have been published to help healthcare professionals and patients in achieving optimal management for knee OA [6-9]. Notwithstanding the publication of guidelines, there still appears to be a large gap between best practice as defined by scientific evidence and actual clinical care in knee osteoarthritis as shown from several studies in different countries [10-12]. A recent Norwegian study showed that guideline adherence to non-pharmacological treatment modalities was only 44\% [13]. Adherence to guidelines can be assessed with quality indicators, which are measurable elements in the diagnostic and therapeutic process and based on scientific evidence 
or consensus [14, 15]. A set of 21 quality indicators for the management of OA was developed for the Belgian primary healthcare system [16].

There is thus a clear need for interventions to improve guideline adherence to obtain optimal care for the patients. However, to allow effective intervention strategies, first qualitative research is needed that addresses possible barriers and facilitators to guideline adherence in current care [17]. To date, barriers and facilitators have mainly been studied from the healthcare professionals' perspective [18]. However, patients play a crucial role in upgrading care to better guideline adherence as their experiences, preferences, concerns and care management can substantially influence the decision-making process for optimal knee OA management [19-21].

Therefore, the aim of this study was to investigate barriers and facilitators in current care of knee OA from the patients' perspective.

\section{Methods}

\section{Study design}

To identify barriers and facilitators in the management of knee $O A$, semi-structured face-to-face interviews were conducted with patients. The interview script was based on the Belgian set of quality indicators [16]. This study was described in accordance with the consolidated criteria for reporting Qualitative Research (COREQ checklist) [22].

\section{Study population}

Patients with knee OA were recruited in three different settings: from the interviewers' (JD) general practice population, from the patient population of GP practices in the same region and finally by an advertisement in the monthly magazine of the national federation for patients with rheumatic diseases. In the GP settings a search was performed by the GP in the electronic health record to select eligible patients with a diagnosis of knee OA.

The inclusion criteria for this study were: 1) clinical and/or radiological diagnosis of knee OA, 2) age 40 years and older, 3) no history of inflammatory arthritis, 4) no previous knee surgery and 5) no cognitive dysfunction which prevents participation in the study [23, 24]. The interviewer contacted eligible patients by phone to participate. Before the interview, patients were informed about the study protocol and signed a consent form. All patients were asked about the history of their diagnosis during the interviews.

\section{Data collection}

All interviews were performed by JD, a medical student in postgraduate training for General Practitioner and well trained in communication with patients. An expert (RH) in the field of qualitative research supported the interviewer during the planning and analysis. Interviews were conducted until data saturation was reached. Data saturation was defined as the point when no new ideas emerged in three consecutive interviews [25].

To meet the aim and objectives, a semi-structured interview script was developed. The questions in the script were based on the national set of quality indicators for knee OA [16]. This set was developed with the help of a multidisciplinary Belgian expert panel and based on recommendations 
from international guidelines for knee OA management. The set consisted of 21 measurable quality indicators divided over four care aspects: diagnosis, lifestyle and education, treatment, and followup. For the interview script every quality indicator from the Belgian set was translated into a specific open-ended question. Leading questions were avoided to reduce bias in the participants' responses. To explore in-depth patient's experience with the perceived care, accompanying barriers and facilitators were queried for each quality indicator. The framework of Grol and Wensing was chosen as the theoretical model to structure the identified barriers and facilitators [26, 27]. In this framework six domains are described to categorize different topics to achieve guideline adherence, namely characteristics of: the guideline, the healthcare professional, the patient, the social environment, the health organization and the financial context.

\section{Analysis}

All interviews were audiotaped and transcribed verbatim. Directed content analysis was used to analyze the interviews [28]. Two researchers (JD and DS) independently reviewed all interview transcripts. Words or phrases representing the same concept were clustered into the six domains of the framework. Subnodes were defined for every domain during the coding process and new codes were defined for information that could not be transcribed into the predetermined domains. Discrepancies were discussed with a third researcher $(\mathrm{RH})$ until consensus was reached. Participants were not informed about the study results. Data were analyzed with software package NVIVO 10 (QRS International Pty Ltd, Doncaster, Vic, Australia).

\section{Ethical approval}

The study protocol was presented to the Medical Ethical Committee of the University Hospital in Leuven, Belgium. The study protocol was approved on $13^{\text {th }}$ July 2012 (S54497, Belgian number B322201214707)

\section{Results}

\section{Participants}

Eleven interviews were conducted at patients' homes between December 2013 and February 2015. A twelfth interview was excluded for analysis because the patient also suffered from rheumatoid arthritis. Participants were recruited in three different settings: five via the interviewers' practice, five via other participating General Practitioners, and one via the national magazine for patients. In the interviewers' practice 33 eligible patients were identified in the electronic health record: 20 refused to participate, 8 were not able to participate because they were deceased or had limited communication skills due to cognitive dysfunction. The duration of an interview ranged from 28 to 88 minutes, with a median range of 52 minutes. In total, four men and seven women participated. Their age ranged between 40 and 90 years (mean age was 66.2 years). Eight of the patients were retired. The participating patients were registered in seven general practices in the Flemish speaking region around the Belgian capital area.

\section{Barriers}

In total, 38 unique barriers were described in six potential domains of the framework: three at the domain of the guideline, eight at the domain of the healthcare professional, 15 at the domain of the patient, five at the social environment, five at organization level and finally two at financial level 
(Table 1). Most barriers were registered in the domain of the patient and healthcare professional. Four barriers were mentioned by all patients: disagreement with guideline recommendations, negative experience with drugs, limited comprehension of the disease process in the domain of the patient and poor communication by the healthcare professional in the domain of the professional. The following two barriers were mentioned by fewer than four patients and not mentioned in Table 1: profit gain in the domain of the healthcare professional and poor availability of the healthcare professional in the organization level. Illustrative quotations from patients are listed in figure 1. In what follows, the main barriers in all six domains of the framework are described.

\section{Guideline level}

Some patients reported that they experienced difficulties to put the guideline recommendations into practical use. Especially the guideline advice to start or maintain physical activity was difficult for patients. For example, comorbidity with cardiac or pneumological diseases interfered with sports activities. Several patients also experienced their age as a limitation for surgery. For example, orthopedic specialists are generally reluctant to perform knee joint replacement surgery for patients under 50 years of age [29].

\section{Healthcare professional level}

Eight barriers were reported within this domain. Poor communication with the patient was the most described barrier. Patients experienced they did not receive sufficient medical information about their disease process. The term osteoarthritis was often not even mentioned by doctors or in medical reports. Patients were disappointed to learn that their doctors presented knee OA as a normal aging phenomenon with limited treatment options. Patients concluded that healthcare professionals underestimated the physical complaints and were not supportive enough. The limited consultation time was a major concern because it interfered with good communication and providing patienttailored treatments. Older adults in particular complained that the limited time was often spent on 'more important' comorbidities. Finally, patients mentioned they were referred to a physiotherapist to improve their general condition, but they received no specific training, like strenghtening exercises, for their knee OA.

\section{Patient level}

In this domain patients mentioned 15 barriers. Most patients had limited comprehension of risk factors for knee osteoarthritis and possible treatments. Therefore, their opinion and expectations were not always in accordance with guideline recommendations. For example, all interviewed patients expected radiological investigations to confirm their diagnosis or they underestimated the importance of weight control or physical activity in the treatment process. They often did not consider knee OA a priority health problem, but part of a normal aging or inherited process. Therefore, often significant time passed between the onset of symptoms and the first doctors' visit. In case of comorbidity, patients even gave priority discussing other health problems with their physician. If the diagnosis was confirmed, medication and/or surgery were the only treatment options from the patients' perspective. Furthermore, they were not inclined to follow advice to engage in more physical activity. Lack of time was frequently mentioned as a reason to perform less physical activity. For patients it was sometimes difficult to interpret the priority of non-surgical treatment options such as diet, orthopedic aids and devices, physical activity or medication. Negative experience with drugs was an important reason for patients to discontinue their medication. Pain during physical therapy or insufficient improvement with physical therapy, were other reasons to 
stop their treatment. All patients mentioned fear as an important barrier in some part of their treatment process. Some patients were reluctant to use analgesic medication. They were afraid of addiction, side effects or interaction with other medication. Fear of more pain or falling kept patients from starting physical activity. Some had lack of confidence in the healthcare professional. Patients sometimes did not have enough faith in evidence-based medicine: proven or not by science, they wanted to experience themselves if medication worked or not. Thus, patients indicated 'not providing alternative treatment options' as a reason to stop their treatment and seek alternative medical care. Lack of support by healthcare professionals to keep them motivated was repeatedly mentioned as a reason to discontinue physical activities.

\section{Social environment}

In this domain patients reported five barriers. Patients attached great importance to information from their social environment even though this information was not always based on scientific evidence. Fear for surgical interventions could often be attributed to negative surgical experience or influence from people in the patients' environment. Moreover, orthopedic aids and devices were seen as a form of stigmatization by almost all patients. Patients active in the labor market specifically mentioned lack of acknowledgement. They complained that employers were not inclined to provide alternative work or a workload adapted to their physical conditions.

\section{Organization level}

In this domain patients reported five barriers. Lack of communication between healthcare professionals could delay the treatment process and confused patients in choosing their follow-up. In Belgium patients have the opportunity to make an appointment with a specialist without referral from their GP. They often did not know whom to consult and whether to choose for an orthopedist or rheumatologist. Secondly, the number of reimbursed sessions of physical therapy is limited in Belgium. This was a barrier in order to continue physical therapy. Patients also reported it was difficult to persevere the exercise program, prescribed by their physiotherapist, because they did not have the same equipment at home to insist these exercises. Perseverance of their exercise program was especially difficult for patients who combine work with physical therapy after working hours. For some, this was a reason to stop their physical therapy. Finally, patients indicated that they searched the Internet for reliable information about diagnostic and therapeutic options for knee OA, but were not able to find clear and transparent information.

\section{Financial level}

In this domain patients remarked two barriers. High cost was a common problem in different aspects of this chronic illness: certain medication was not refunded, physical therapy and orthopedic aids are expensive and modifications in patients' homes, such as a stair lift, came at their own expenses.

Moreover, many patients discovered too late in their treatment process whether certain costs were refunded or not. This lack of transparency often led to interruption of the treatment process.

\section{Facilitators}

Twenty unique facilitators were mentioned in five of the six domains (Table 2). All facilitators had an opposing barrier. Hence, only the most striking facilitators were reported: good communication and a confident relationship with the healthcare professional were imperative for sustainable follow-up. Positive experience with physical therapy was an important factor to maintain (exercise) treatment. Finally, social support kept patients motivated for exercise treatment. 


\section{Discussion}

This study is the first to explore barriers and facilitators in the management of knee OA from the patients' perspective with an interview script based on quality indicators. The script, with openended questions, was a significant aid to structurally describe non-adherence to guidelines. In total, 38 unique barriers for guideline adherence were reported and categorized within six domains of an evidence-based framework, including characteristics of: the guideline, healthcare professional, patient, social environment, organization and financial context. Most barriers were formulated in the domains of the patient and the healthcare professional. All interviewed patients mentioned: limited comprehension of the disease process, disagreement with guideline recommendations, negative experience with drugs and poor communication by the professional as barriers. Also 20 facilitators were identified. Important facilitators for guideline adherence were: good relationship with the healthcare professional and positive experience with treatment modalities.

This study clearly shows that patients in our Belgian setting lack sufficient understanding of the disease process. Patients often see knee $O A$ as a natural sign of aging [30,31]. This may inhibit them from considering prevention and can play a role in time delay between onset of symptoms and a doctor's visit. In this study, all patients also indicated pain as the most important OA symptom to seek medical advice [32-34]. Consequently, the initial OA care is mainly focused on alleviating pain with pharmacotherapy, while the importance of physical therapy and weight control is neglected or overlooked. Furthermore, all patients mentioned disagreement with evidence-based recommendations from their healthcare professionals in different stages of the knee $O A$ management. For example, all patients insisted on further medical imaging to confirm the diagnosis, even when this is not strictly recommended in the guidelines [23,24]. Physical therapy is an important pillar in the conservative treatment of knee $\mathrm{OA}$, but most patients do not recognize it as a treatment option or mentioned lack of time or money for physical therapy [6-9]. Moreover, patients considered it as potentially dangerous, with fear of (more) pain or aggravation of the disease. A previous study already revealed that there is considerable uncertainty among older adults about the role of exercise and physical activity in the management of knee pain [35]. Participants apparently doubted about whether physical therapy and exercise could improve pain and slow the progression of a knee problem. Disagreement with guideline recommendations has considerable influence on the diagnostic and therapeutic approach of knee OA. Better knowledge about the disease process, including the importance of weight control and sufficient physical activity as primary selfmanagement options, is not only important to improve guideline adherence, but also to deliver more patient-centered care [36]. Patients should receive as little as possible contradictory information by healthcare professionals, their environment or over the Internet. Contradictory information hinders patients to identify themselves with specific goals and to move towards a more intrinsic form of motivation. In facilitating patient-centered care and shared decision making, a fundamental step is for healthcare professionals to elicit patients' expectations; discuss, and correct any of their misperceptions, expectations or fears [37]. An instructive website, self-management tools, patient decision aids, or Shared Decision Making Sheets for professionals, are some patienttailored strategies that could be developed to improve adherence.

In this study, patients mentioned barriers to acquire disease-related information, to adjust their lifestyle behaviors and to some non-surgical treatment options. Similar barriers are revealed in the management of other chronic diseases. For example, barriers in the management of lower back pain 
include: poor understanding of natural history, belief that imaging is necessary to find 'the cause' of the pain, influence of previous experience and social environment on patients' expectations, and incongruence of these expectations with guideline recommendations [37]. Similar barriers are defined in diabetes management: lack of knowledge about the disease process, influence of comorbidities, lack of social support and lack of financial resources have a negative impact on guideline adherence [38]. Besides, knee OA is a chronic disease that does not only affect older people. This study also clearly indicates barriers from younger patients with knee OA. They often struggle to maintain their work activities because of pain and impaired mobility. For younger patients with knee OA, patient-tailored strategies should include an assessment of their occupational situation, in order to facilitate moderation with employers if work floor adjustments or alternative work could be beneficial.

This study approached a common problem from a perspective that has been rarely studied. The strength of this study is that non-adherence to guideline recommendations was analyzed from the patient's perspective. In addition, the framework of Grol and Wensing was an added value to identify and describe the barriers. After all, 38 unique barriers were demonstrated by structuring barriers and facilitators in six different domains. Furthermore, the domains provide the opportunity to clearly differentiate more universal barriers and facilitators that are not only limited to a Belgian setting. On the other hand, limitations to consider are recruitment of patients and potential bias by using semistructured interviews. Patients were recruited from seven general practices in the Flemish speaking region around the capital area and not all eligible patients were able or willing to participate. Hence, answers could be biased because patients were directly influenced by their own experience with knee OA. However, we continued interviewing patients until data saturation was reached. In addition, interpretation bias was reduced by analyzing all transcripts by two independent researchers. Finally, this qualitative study is not conducted to be representative in terms of statistical generalizability. However, barriers mentioned by all patients could be given priority in further quantitative research or in the development of patient-tailored intervention strategies.

In conclusion, clear barriers and facilitators for guideline adherence were identified with semistructured interviews based on quality indicators. Barriers were mainly identified in the domains of the patient and the healthcare professional. Patient-tailored strategies to improve patients' knowledge, self-management and communication with healthcare professionals, for example regarding shared-decision making, could be helpful to improve guideline adherence.

\section{Acknowledgements}

We would like to thank the patients and healthcare professionals who participated in the study. The data were part of the co-authors' (JD) Master thesis.

\section{Disclosure}

The authors report no conflict of interest in this article. 


\section{References}

1. Johnson VL, Hunter DJ. The epidemiology of osteoarthritis. Best practice \& research Clinical rheumatology. 2014;28(1):5-15.

2. Vos T, Flaxman AD, Naghavi M, Lozano R, Michaud C, Ezzati M, et al. Years lived with disability (YLDs) for 1160 sequelae of 289 diseases and injuries 1990-2010: a systematic analysis for the Global Burden of Disease Study 2010. Lancet. 2012;380(9859):2163-96.

3. Silverwood V, Blagojevic-Bucknall M, Jinks C, Jordan JL, Protheroe J, Jordan KP. Current evidence on risk factors for knee osteoarthritis in older adults: a systematic review and metaanalysis. Osteoarthritis and cartilage / OARS, Osteoarthritis Research Society. 2015;23(4):507-15.

4. Dekker J, Peter W, van der Leeden M, Lems WF. [Exercise therapy in hip or knee osteoarthritis]. Nederlands tijdschrift voor geneeskunde. 2011;155(30-31):A3462.

5. Cross M, Smith E, Hoy D, Nolte S, Ackerman I, Fransen M, et al. The global burden of hip and knee osteoarthritis: estimates from the global burden of disease 2010 study. Annals of the rheumatic diseases. 2014;73(7):1323-30.

6. Fernandes L, Hagen KB, Bijlsma JW, Andreassen O, Christensen P, Conaghan PG, et al. EULAR recommendations for the non-pharmacological core management of hip and knee osteoarthritis. Annals of the rheumatic diseases. 2013;72(7):1125-35.

7. McAlindon TE, Bannuru RR, Sullivan MC, Arden NK, Berenbaum F, Bierma-Zeinstra SM, et al. OARSI guidelines for the non-surgical management of knee osteoarthritis. Osteoarthritis and cartilage / OARS, Osteoarthritis Research Society. 2014;22(3):363-88.

8. National Institute for Health and Care Excellence (NICE) quality standard 87: osteoarthritis, 2015. [Internet. Accessed August 28, 2015.] Available from: http://guidance.nice.org.uk/qs87.

9. Treatment of osteoarthritis of the knee. Evidence-based guideline 2th edition, Published May 18,2013. [Internet. Accessed November 9, 2015.] Available from:

http://www.aaos.org/Research/guidelines/TreatmentofOsteoarthritisoftheKneeGuideline.pdf.

10. Voelker R. Few adults with knee osteoarthritis meet national guidelines for physical activity. Jama. 2011;306(13):1428, 30.

11. DeHaan MN, Guzman J, Bayley MT, Bell MJ. Knee osteoarthritis clinical practice guidelines -how are we doing? The Journal of rheumatology. 2007;34(10):2099-105.

12. Dunlop DD, Song J, Semanik PA, Chang RW, Sharma L, Bathon JM, et al. Objective physical activity measurement in the osteoarthritis initiative: Are guidelines being met? Arthritis and rheumatism. 2011;63(11):3372-82.

13. Gronhaug G, Hagfors J, Borch I, Osteras N, Hagen KB. Perceived quality of health care services among people with osteoarthritis - results from a nationwide survey. Patient preference and adherence. 2015;9:1255-61.

14. Jansen MJ, Hendriks EJ, Oostendorp RA, Dekker J, De Bie RA. Quality indicators indicate good adherence to the clinical practice guideline on "Osteoarthritis of the hip and knee" and few prognostic factors influence outcome indicators: a prospective cohort study. European journal of physical and rehabilitation medicine. 2010;46(3):337-45.

15. Campbell SM, Braspenning J, Hutchinson A, Marshall M. Research methods used in developing and applying quality indicators in primary care. Quality \& safety in health care. 2002;11(4):358-64.

16. Grypdonck L, Aertgeerts B, Luyten F, Wollersheim H, Bellemans J, Peers K, et al. Development of quality indicators for an integrated approach of knee osteoarthritis. The Journal of rheumatology. 2014;41(6):1155-62.

17. Bero LA, Grilli R, Grimshaw JM, Harvey E, Oxman AD, Thomson MA. Closing the gap between research and practice: an overview of systematic reviews of interventions to promote the implementation of research findings. The Cochrane Effective Practice and Organization of Care Review Group. BMJ (Clinical research ed). 1998;317(7156):465-8.

18. Brody DS. The patient's role in clinical decision-making. Annals of internal medicine. 1980;93(5):718-22. 
19. Van Den Boogaard E, Hermens RP, Leschot NJ, Baron R, Vollebergh JH, Bernardus RE, et al. Identification of barriers for good adherence to a guideline on recurrent miscarriage. Acta obstetricia et gynecologica Scandinavica. 2011;90(2):186-91.

20. Horne R, Weinman J. Patients' beliefs about prescribed medicines and their role in adherence to treatment in chronic physical illness. Journal of psychosomatic research. 1999;47(6):555-67.

21. Mitchell HL, Hurley MV. Management of chronic knee pain: a survey of patient preferences and treatment received. BMC musculoskeletal disorders. 2008;9:123.

22. Tong A, Sainsbury P, Craig J. Consolidated criteria for reporting qualitative research (COREQ): a 32-item checklist for interviews and focus groups. International journal for quality in health care : journal of the International Society for Quality in Health Care / ISQua. 2007;19(6):349-57.

23. Altman R, Asch E, Bloch D, Bole G, Borenstein D, Brandt K, et al. Development of criteria for the classification and reporting of osteoarthritis. Classification of osteoarthritis of the knee.

Diagnostic and Therapeutic Criteria Committee of the American Rheumatism Association. Arthritis and rheumatism. 1986;29(8):1039-49.

24. Zhang W, Doherty M, Peat G, Bierma-Zeinstra MA, Arden NK, Bresnihan B, et al. EULAR evidence-based recommendations for the diagnosis of knee osteoarthritis. Annals of the rheumatic diseases. 2010;69(3):483-9.

25. Francis JJ, Johnston M, Robertson C, Glidewell L, Entwistle V, Eccles MP, et al. What is an adequate sample size? Operationalising data saturation for theory-based interview studies.

Psychology \& health. 2010;25(10):1229-45.

26. Grol R, Wensing M, Eccles M. Improving patient care: the implementation of change in clinical practice. Elsevier Butterworth Heinemann, 2005.

27. Flottorp SA, Oxman AD, Krause J, Musila NR, Wensing M, Godycki-Cwirko M, et al. A checklist for identifying determinants of practice: a systematic review and synthesis of frameworks and taxonomies of factors that prevent or enable improvements in healthcare professional practice. Implementation science : IS. 2013;8:35.

28. Hsieh HF, Shannon SE. Three approaches to qualitative content analysis. Qualitative health research. 2005;15(9):1277-88.

29. McHugh GA, Campbell M, Silman AJ, Kay PR, Luker KA. Patients waiting for a hip or knee joint replacement: is there any prioritization for surgery? Journal of evaluation in clinical practice. 2008;14(3):361-7.

30. Turner AP, Barlow JH, Buszewicz M, Atkinson A, Rait G. Beliefs about the causes of osteoarthritis among primary care patients. Arthritis and rheumatism. 2007;57(2):267-71.

31. Ali F, Jinks C, Ong BN. "...Keep mobile, I think that's half the battle." A qualitative study of prevention of knee pain in symptomless older adults. BMC public health. 2012;12:753.

32. Kao MH, Tsai YF. Living experiences of middle-aged adults with early knee osteoarthritis in prediagnostic phase. Disability and rehabilitation. 2012;34(21):1827-34.

33. Bidaut-Russell M, Gabriel SE. Adverse gastrointestinal effects of NSAIDs: consequences and costs. Best practice \& research Clinical gastroenterology. 2001;15(5):739-53.

34. Altman RD, Hochberg M, Murphy WA, Jr., Wolfe F, Lequesne M. Atlas of individual radiographic features in osteoarthritis. Osteoarthritis and cartilage / OARS, Osteoarthritis Research Society. 1995;3 Suppl A:3-70.

35. Holden MA, Nicholls EE, Young J, Hay EM, Foster NE. Role of exercise for knee pain: what do older adults in the community think? Arthritis care \& research. 2012;64(10):1554-64.

36. Mead N, Bower P. Patient-centredness: a conceptual framework and review of the empirical literature. Social science \& medicine (1982). 2000;51(7):1087-110.

37. Hoffmann TC, Del Mar CB, Strong J, Mai J. Patients' expectations of acute low back pain management: implications for evidence uptake. BMC family practice. 2013;14:7.

38. Nam S, Chesla C, Stotts NA, Kroon L, Janson SL. Barriers to diabetes management: patient and provider factors. Diabetes research and clinical practice. 2011;93(1):1-9. 
Table 1. Barriers related to guideline adherence for knee osteoarthritis according to patients. Barriers mentioned by all patients are shown in bold type.

\begin{tabular}{|c|c|c|c|c|c|}
\hline $\begin{array}{l}\text { Guideline } \\
\text { (total } n=3 \text { ) }\end{array}$ & $\begin{array}{l}\text { Health care } \\
\text { Professional } \\
\text { (total } n=8 \text { ) }\end{array}$ & $\begin{array}{l}\text { Patient } \\
\text { (total } n=15 \text { ) }\end{array}$ & $\begin{array}{l}\text { Social } \\
\text { (total } n=5)\end{array}$ & $\begin{array}{l}\text { Organisation } \\
\text { (total } n=5 \text { ) }\end{array}$ & $\begin{array}{l}\text { Financial } \\
\text { context } \\
\text { (total } n=2 \text { ) }\end{array}$ \\
\hline $\begin{array}{l}\text { - Recommendati } \\
\text { ons not adapted } \\
\text { for practical } \\
\text { setting } \\
\text { - Co-morbidity } \\
\text { intervenes with } \\
\text { treatment } \\
\text { options } \\
\text { - Age intervenes } \\
\text { with treatment } \\
\text { options }\end{array}$ & $\begin{array}{l}\text { - Poor } \\
\text { communicati } \\
\text { on with the } \\
\text { patient } \\
\text { - Limited time } \\
\text { to provide } \\
\text { information of } \\
\text { the disease } \\
\text { process } \\
\text { - Limited time } \\
\text { to inform } \\
\text { patients about } \\
\text { different } \\
\text { treatment } \\
\text { options } \\
\text { - Advice not in } \\
\text { accordance } \\
\text { with the } \\
\text { guidelines } \\
\text { Advice not in } \\
\text { accordance } \\
\text { with patients } \\
\text { opinion } \\
\text { No } \\
\text { recognition of } \\
\text { the medical } \\
\text { problem } \\
\text { Not } \\
\text { supportive in } \\
\text { the treatment } \\
\text { process } \\
\text { Limited time to } \\
\text { provide } \\
\text { patient } \\
\text { tailored } \\
\text { treatment } \\
\text { options } \\
\text { - }\end{array}$ & 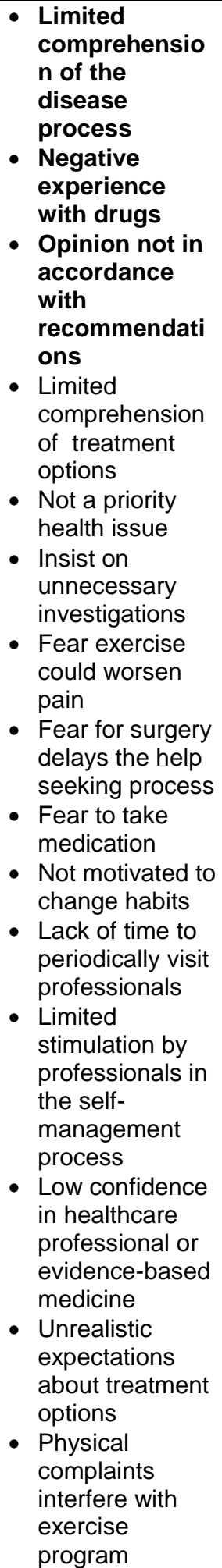 & $\begin{array}{l}\text { - Source of } \\
\text { false } \\
\text { information } \\
\text { about the } \\
\text { disease } \\
\text { process } \\
\text { - Fear for } \\
\text { stigmatizati } \\
\text { on when } \\
\text { using aids } \\
\text { and } \\
\text { devices } \\
\text { - Lack of } \\
\text { adjustment } \\
\text { s on the } \\
\text { work floor } \\
\text { - No tailored } \\
\text { sport } \\
\text { facilities } \\
\text { available } \\
\text { - Negative } \\
\text { influence } \\
\text { on } \\
\text { treatment } \\
\text { options }\end{array}$ & $\begin{array}{l}\text { - Limited } \\
\text { communicati } \\
\text { on between } \\
\text { caretakers } \\
\text { - Organization } \\
\text { of healthcare } \\
\text { with limited } \\
\text { sessions for } \\
\text { physical } \\
\text { therapy and } \\
\text { no obligation } \\
\text { for referral } \\
\text { - Patients lack } \\
\text { equipment to } \\
\text { sustain } \\
\text { treatment in } \\
\text { their home } \\
\text { setting } \\
\text { - Difficult to } \\
\text { combine } \\
\text { work and } \\
\text { physical } \\
\text { therapy } \\
\text { - No } \\
\text { transparent } \\
\text { information } \\
\text { available on } \\
\text { the internet }\end{array}$ & $\begin{array}{l}\text { - High cost } \\
\text { for } \\
\text { medication } \\
\text {, aids and } \\
\text { devices } \\
\text { - No } \\
\text { transparen } \\
\text { ce about } \\
\text { refund of } \\
\text { care }\end{array}$ \\
\hline
\end{tabular}


Table 2. Facilitators related to guideline adherence for knee osteoarthritis according to patients.

\begin{tabular}{|c|c|c|c|c|c|}
\hline $\begin{array}{l}\text { Guideline } \\
(n=1)\end{array}$ & $\begin{array}{l}\text { Health care } \\
\text { professional } \\
(n=5)\end{array}$ & $\begin{array}{l}\text { Patient } \\
(n=8)\end{array}$ & $\begin{array}{l}\text { Social } \\
(n=3)\end{array}$ & $\begin{array}{l}\text { Organisation } \\
(n=3)\end{array}$ & $\begin{array}{l}\text { Financial } \\
\text { context }\end{array}$ \\
\hline $\begin{array}{l}\text { - Tailored } \\
\text { treatment } \\
\text { options } \\
\text { available in } \\
\text { case of } \\
\text { comorbidity }\end{array}$ & 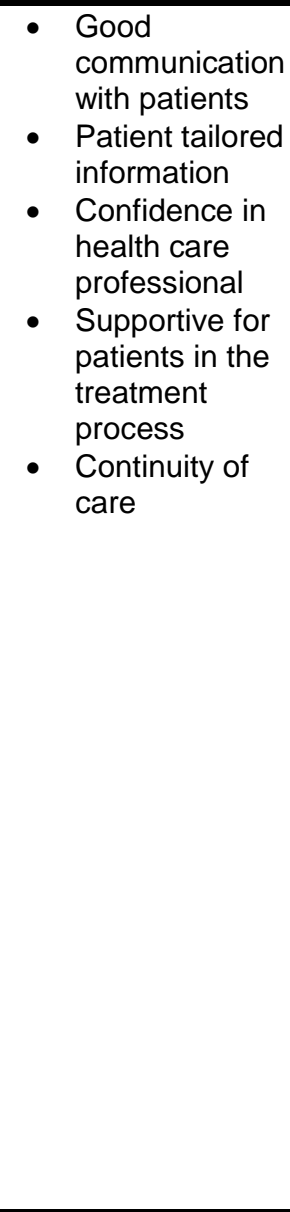 & $\begin{array}{ll}\text { - } & \text { Self- } \\
\text { management } \\
\text { capacities } \\
\text { Motivated } \\
\text { and positive } \\
\text { attitude } \\
\text { Realistic } \\
\text { expectations } \\
\text { about } \\
\text { treatment } \\
\text { options } \\
\text { Confidence } \\
\text { in } \\
\text { professional } \\
\text { Positive } \\
\text { experience } \\
\text { with } \\
\text { treatment } \\
\text { Sufficient } \\
\text { knowledge } \\
\text { about } \\
\text { disease } \\
\text { process } \\
\text { Hope for } \\
\text { improvement } \\
\text { (after } \\
\text { operation) } \\
\text { Agreement } \\
\text { with } \\
\text { professional } \\
\text { about } \\
\text { treatment } \\
\text { modalities }\end{array}$ & $\begin{array}{ll}\text { - } & \text { Source of } \\
\text { reliable } \\
\text { information } \\
\text { - } & \text { Positive } \\
\text { empowerment } \\
\text { from } \\
\text { environment } \\
\text { - } \quad \text { Practical } \\
\text { support in } \\
\text { case of } \\
\text { disability }\end{array}$ & 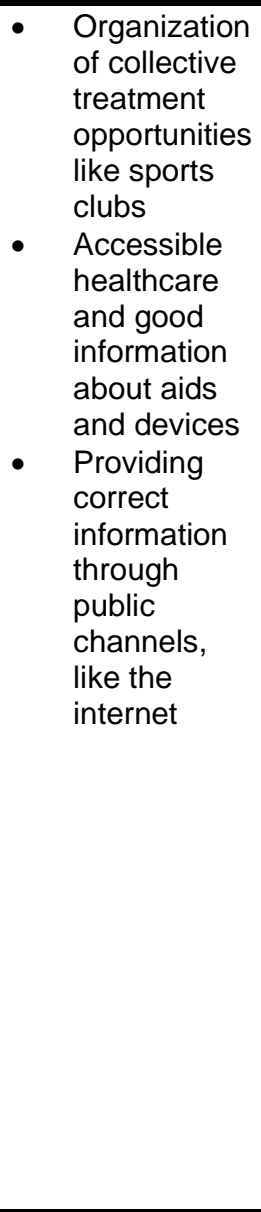 & 1 \\
\hline
\end{tabular}




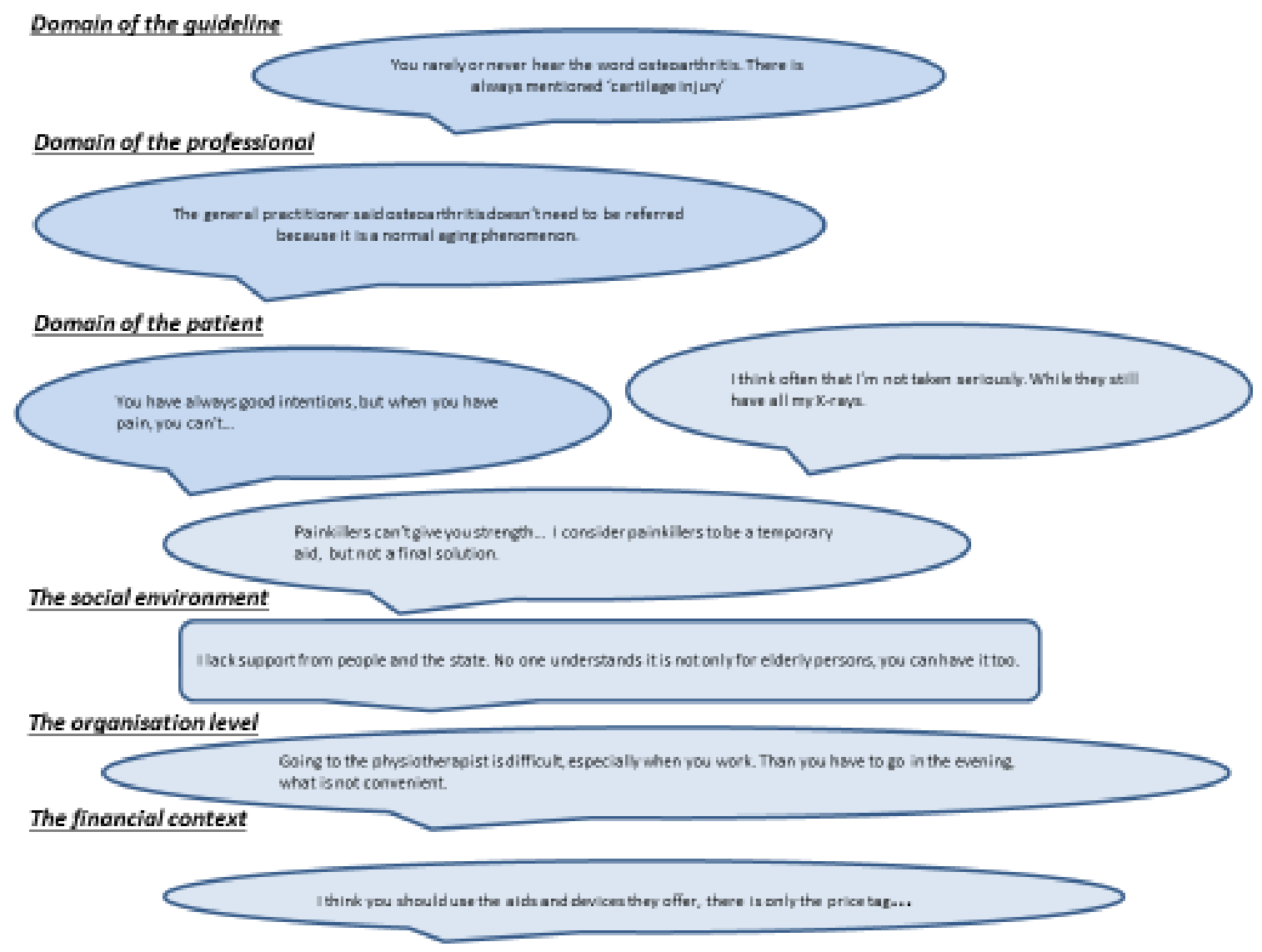

Figure 1. Illustrative quotations from patients concering adherence to knee OA management 